\title{
Simulation experiments and validation for considering bus priority treatments in small cites: The case of Hawassa city, Ethiopia
}

\author{
Robel Desta $^{{ }^{1}}$, Bikila Teklu ${ }^{2}$, Mihret Dananto ${ }^{3}$ \\ ${ }^{1}$ Hawassa University, Institute of Technology - School of Civil Engineering, P.O.Box: 1528, Hawassa, ETHIOPIA \\ ${ }^{2}$ Addis Ababa University, Institute of Technology (AAiT) - School of Civil and Environmental Engineering, P.O.Box: 385, Addis Ababa, ETHIOPIA \\ ${ }^{3}$ Hawassa University, Institute of Technology - School of Bio-system and Environmental Engineering, P.O.Box: 05, Hawassa, ETHIOPIA \\ Corresponding Author:e-mail: ugetrobin@gmail.com (and/or) robeld@hu.edu.et, Tel+251-916035019
}

\begin{abstract}
In this paper, the development of network and intersection simulation models using microsimulation tool, along with validation of the models is studied. The validated microscopic simulation models can be utilized for further evaluation of various traffic operational conditions, such as bus priority measures for improving bus service performance. Traffic planning should put emphasis on the promotion of public transport to ensure sustainability. In planning transport setups, computer models ensure the analysis of different alternative public transport options like bus priority treatments. Various traffic performance indicators like; headway, delay, queue length, travel speed and travel time were considered during the validation of the simulation models. The obtained results from the developed simulation experiments and the statistical comparison with the field traffic behavior assured that the models accurately represent the actual traffic nature with less than $10 \%$ margin of error. The simulation experiment results show that the City's road corridors can accurately be created in microsimulation tools before conducting an impact analysis for alternative transportation strategies.
\end{abstract}

Keywords: Microscopic simulation, microsimulation tool, public transport, traffic performance indicators, validation

DOI: http://dx.doi.org/10.4314/ijest.v10i4.3

\section{Introduction}

It is a fact that traffic delays in cities and the effect of increasing urban sprawl can be controlled better by considering interconnected public transport networks. Micro-simulation models ensure a better and 'purer' representation of real driver behavior and network performance, as these modeling tools are the only available option with the capability to examine certain complex traffic problems (Fox, 2011). Many of the cities around the world are experiencing alertly growing traffic congestion in urban areas and motorway networks. The impact of congestion could be calmed down by optimizing the performance of the traffic infrastructure through various traffic management and operational strategies. The effectiveness of the proposed mitigation measures are examined in carefully designed experiments for a real highway stretch with real demand scenarios. Furthermore, the behavior of the proposed experimental mitigation schemes is examined and evaluated through microscopic simulation along with refined validation (Papadopoulouet al., 2018).

Currently, the impacts of various public transport improvement approaches are verified by using various powerful traffic microsimulation tools like PTV VISSIM (Planung Transport Verkehr - VerkehrInStädten - SIMulations model). However, unless efficient validations are made for the created networks or intersection models, erroneous results could be obtained as the models may not represent the reality. Therefore, the created simulation models need to be validated by considering various traffic parameters before conducting any priority strategy analysis. Various studies have been conducted in the past and recent years with traffic microsimulation tools, such as, for example, Algers et al. (1997), Jepson and Ferreira (1999), Fox and Liu (2000), Fox et al. (2000), Papageorgiou et al. (2006), Morellato \& Sdun (2010), Vedagiri and Jain (2012), Dudutaet al. (2012), Oshyani 
and Cats (2016), and Papadopoulou et al. (2018). However, there is still a need for much deeper investigation and this study presents several novelties contributing for:

- a consistent and practical approach in developing a simulation model for considering various bus priority treatments with multimodal traffic micro-simulation tool (PTV VISSIM 9.0-07);

- verifying the validity of the created models using multiple traffic performance indicators like headway, delay, queue length, travel speed and travel time.

\section{Materials and Methods}

The study area:

The study was conducted in Hawassa City, Ethiopia that covers an area of approximately $50 \mathrm{~km} 2$ and is located about $275 \mathrm{~km}$ from Addis Ababa along the road connecting Ethiopia and Kenya. It is an administrative center and /or regional capital of Southern Nations, Nationalities and Peoples Regional (SNNPR) state. It is found in Sidama Zone on the eastern shore of Lake Hawassa, which is one of the Great Rift Valley Lakes. It is approximately located between $7^{\circ} 00^{\prime} 36^{\prime \prime} \mathrm{N}$ Latitude and $38^{\circ} 29^{\prime} 54^{\prime \prime} \mathrm{E}$ Longitude, and at an average elevation of $1705 \mathrm{~m}$ above mean sea level (a.m.s.l). "VISSIM is a microscopic, time step and behavior based simulation model developed to analyze the full range of functionally classified roadways and public transportation operations" (Papageorgiou et al., 2006). For the experiments in this study, extensive data are required for developing the simulation models and for performing validation of the models. In developing the simulation models, three scenarios were considered for efficient experimentation:

- The Ker-awud area signalized T-intersection (3 legged)

- The Tirufat area signalized crossroad intersection (4 legged)

- A $1.5 \mathrm{~km}$ road network from Piazza to Atote areas with the two intersections

Actual field data on classified intersection volume at each turn of the legs by vehicle type, traffic signal cycle lengths, traffic composition, road geometry, categorized average vehicle sizes, mid-block traffic volume, spot speeds and observation data on traffic operation were piled up for developing the simulation models in VISSIM. Further data were collected from field for samples of vehicles based on standard literature. Such data include, actual vehicle categorized travel time (Garber and Hoel, 2008), time headways (Shawn et al., 1998), categorized total traffic delays (Garber and Hoel, 2008; Bhavsaret al., 2007), queue lengths (Shawn et al., 1998) and speed data (Garber and Hoel, 2008; Currin, 2001) to verify the validity of the simulation results with the actual traffic conditions. Accordingly, the summarized data collected based on the above sampling strategies were utilized in the development of the simulation models.

\section{Theory/ Calculation}

\subsection{Creating the simulation experiment models}

During the simulation experiments, the actual field collected data were fed in VISSIM along with the actual signal cycle lengths. The actual number of lanes in all approaches is four with two directional flows. The links and connectors of the models were created on the scaled satellite background map of the area along with all the actual traffic and geometric data. The actual lane widths are $3 \mathrm{~m}$ at Piazza (Figure 1) and $3.5 \mathrm{~m}$ at Tirufat (Figure 2). In addition, the actual median widths are $3 \mathrm{~m}$ at Piazza (Figure 1) and $0.5 \mathrm{~m}$ at Tirufat (Figure 2), which were defined when creating the links and connectors.

\subsection{Routing decision and vehicle attributes}

Defining vehicle routes (static vehicle route decision) was configured based on the actual field conditions considering the direction of the link flows (Figure1). Then, link relative flows were entered in each direction for each movement types of the intersection. Each routing decisions show the branches of possible movements with their corresponding relative flows/traffic volumes. Before inserting the relative vehicle volumes at each leg, new vehicle compositions were defined for those vehicle types that do not exist by default in VISSIM to represent the actual vehicle types in the City.

\subsection{Signal controller}

When defining the signal controllers, all the signalized intersections in the City were considered as 'fixed time' in which the signal controllers have a preset sequence of signal phases to be displayed in cyclic repetitive order. The total cycle time at each intersection was divided into the corresponding measured red, green and amber times. Signal heads were carefully assigned for each intersection legs with the corresponding signal group of the corridor. For the $1.5 \mathrm{~km}$ study network, all the intersections and geometric elements of the corridor were defined (Figure 3). 


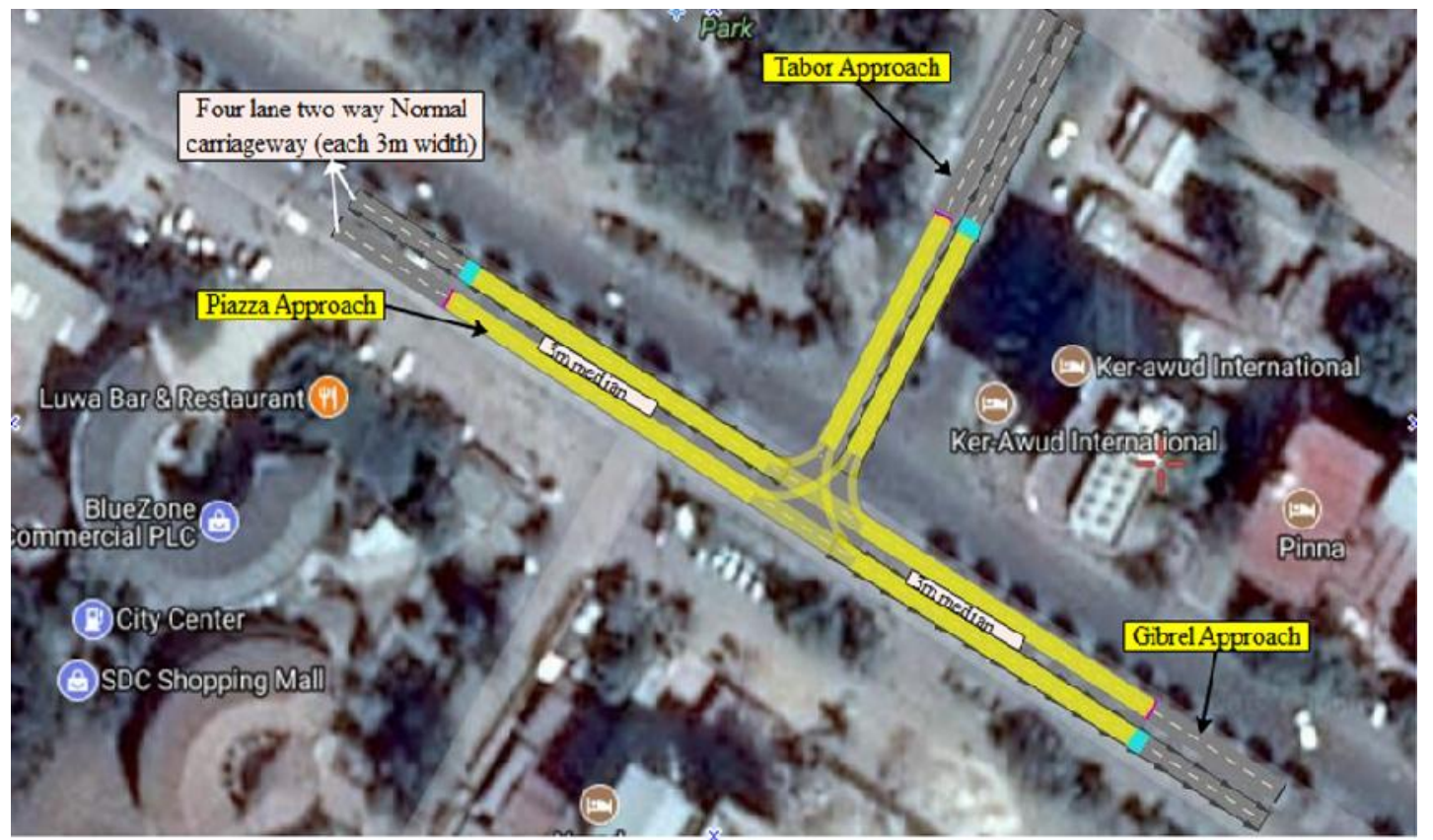

Figure 1: Snapshot of simulation model with the vehicle routes for the first scenario (3-legged intersection)

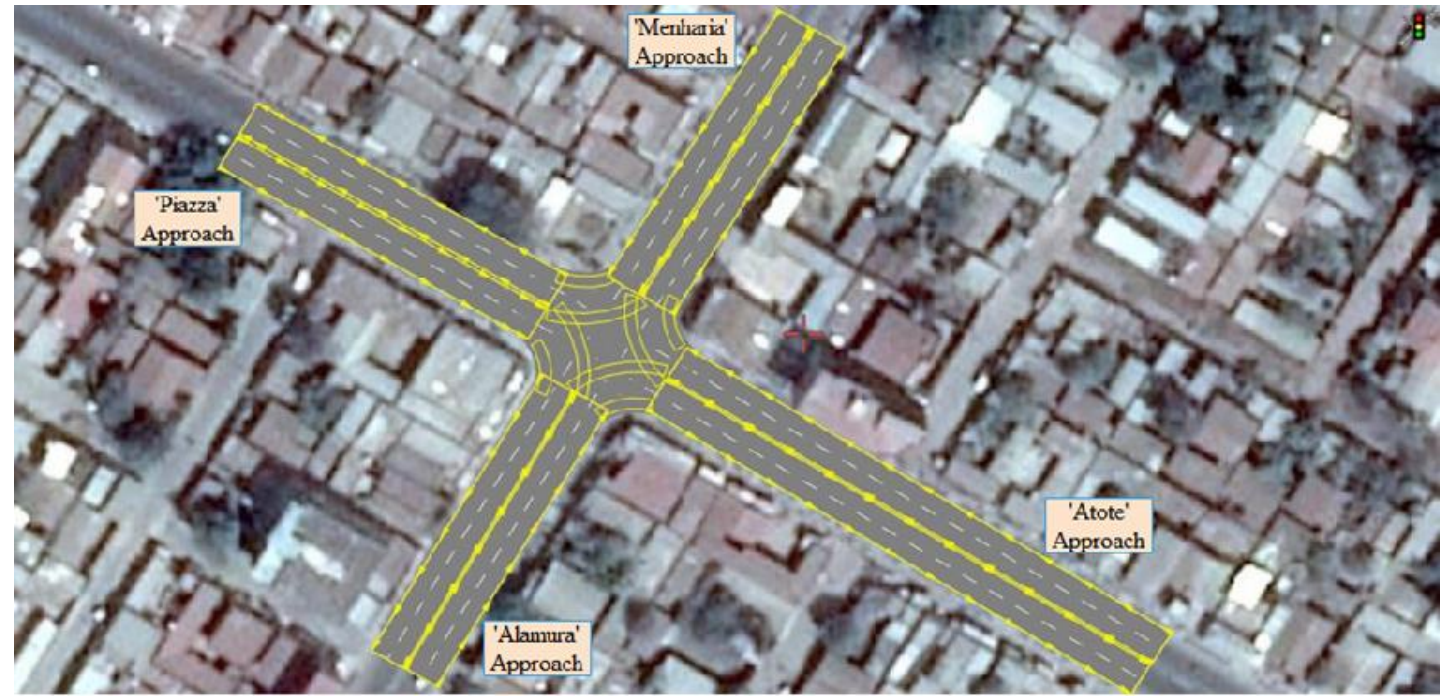

Figure 2:Snapshot of simulation model with the links, splined connectors and reduced speed areas for the second scenario (4legged intersection) 


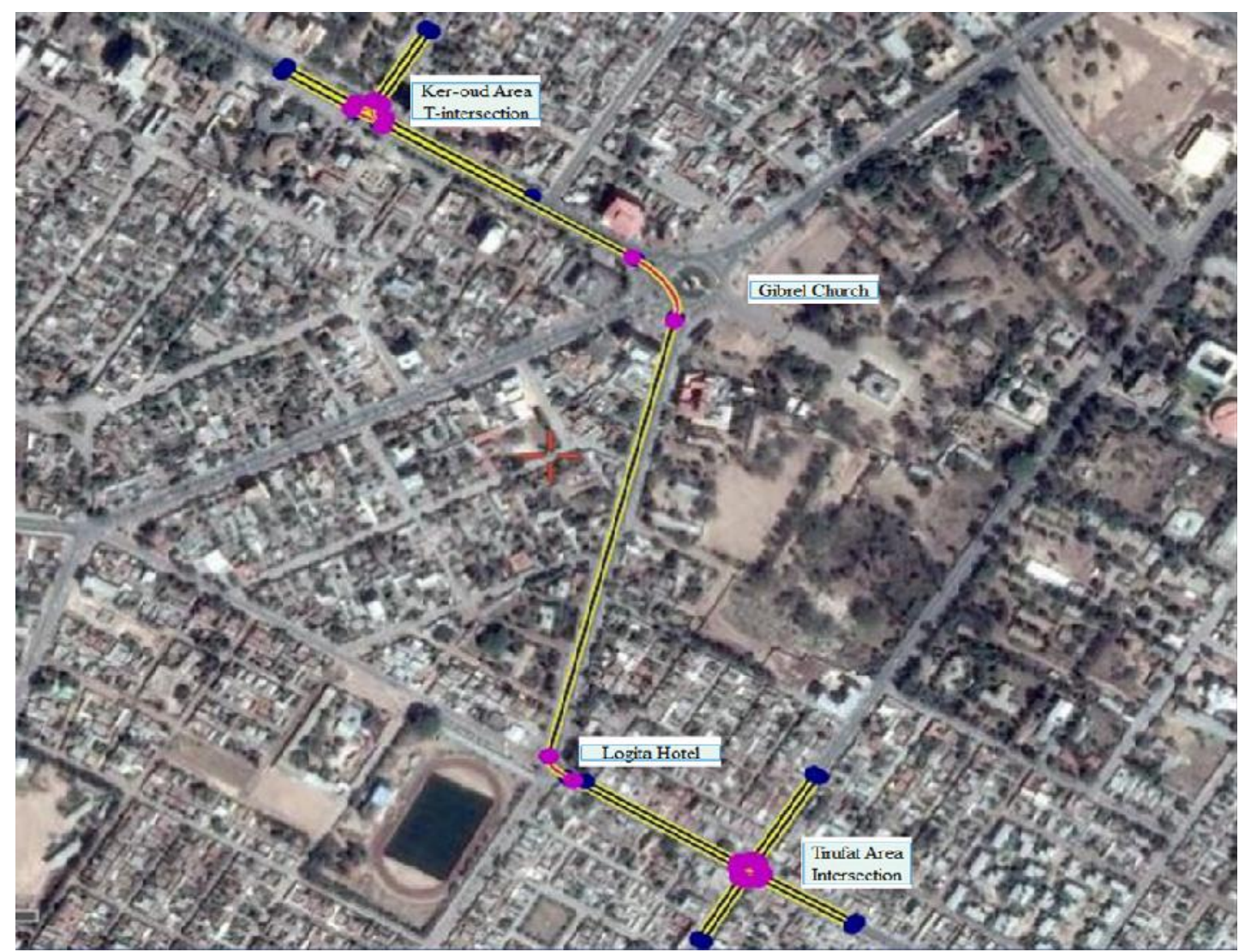

Figure 3:Snapshot of the simulation model in the third scenario (1.5km road network)

After all the models were properly created in VISSIM with the actual data, the proceeding approach was performing the simulation run, which takes $3600 \mathrm{sec}$ to complete. The generated analysis results were carefully extracted from the VISSIM results directory for the given volume of traffic.

\section{Results and Discussion}

For each of the simulation experiments, extensive results were collected for various traffic performance indicators. The simulation results were extracted in various forms like node evaluation for collecting selected basic outputs, direct outputs for collecting various cumulative results and travel time measurement within a defined $60 \mathrm{~m}$ segment to get travel time and delay values. Then, the results were imported to excel and statistical analysis was performed to make use of the data for appropriate comparison.

\subsection{Validation of the simulation experiments}

The validation is concerned with the overall process of comparing the model and its behavior to the real system. In general, if two sets of output data compare "favorably", then the model of the existing system is considered "valid". For any validation to be accurate, the error obtained between the simulated and the real data should not be greater than $10 \%$ (Vedagiri and Jain, 2012). For making the validation, traffic parameters from the simulation results were carefully analyzed in order to match the selected measures of effectiveness with the simulated outputs. Validation of the Ker-awud and Tirufat intersections was performed by comparing parameters like headways, total delays, queue length and speeds of the simulated intersections with the field measured data. Moreover, validation of the total study corridor was done by comparing the total travel time over the defined road segment.

To make the comparison of vehicle delays and time headways near the two intersections, frequency distribution tables were formed for the headway and delay data from VISSIM and field. The validation approach in this study considered multiple criteria to assure the strength of the relationship between the simulated and existing situations. To compare observed and VISSIM headways, statistical frequency plots were drawn on excel (Figure 4-5). 

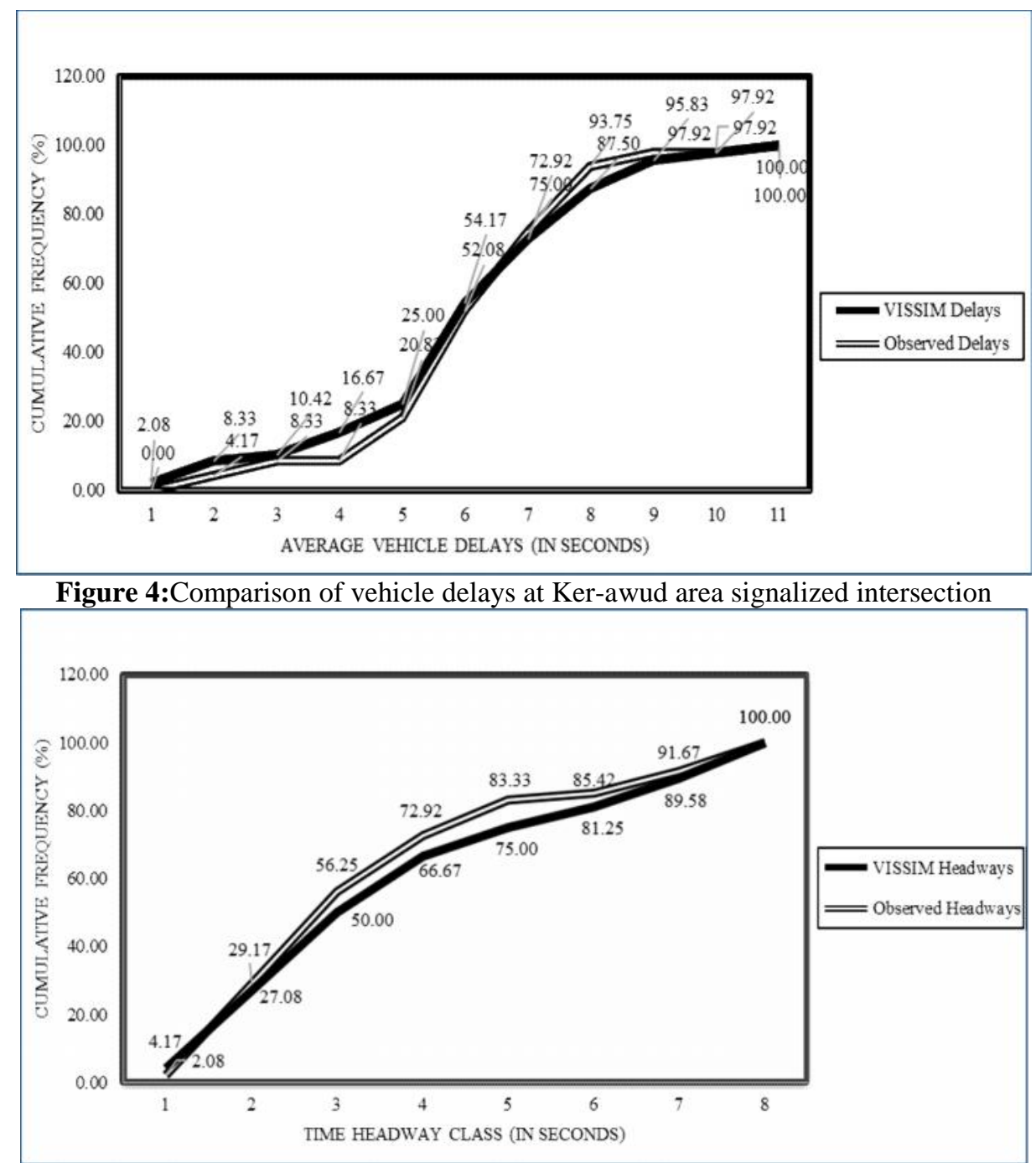

Figure 5:Comparison of time headways at Tirufat area signalized intersection

In order to make the validation of the model by comparing vehicle delays, the measured vehicle travel time was compared with the ideal travel time in order to obtain the field vehicle delays. A statistical frequency distribution table was generated to make the comparison between the simulated vehicle delays with the observed vehicle delays. In determining the average queue length, the lane use behavior had been considered in such a way that the actual number of one directional lanes in field are two in number; but, the lanes are utilized in three or four vehicle lines when forming a queue as if the numbers of lanes are three or four. So, adjustments were made when measuring the field queue lengths, since the simulated queue lengths are only in two lines for one directional vehicular flow. Therefore, considering samples of a platoon of queues, the average tape measured metric queue lengths were determined at the intersections. "Time headway is the time between successive vehicles as they pass a point on a lane or roadway measured from front bumper to front bumper" (Garber and Hoel, 2008). As a result, headway data have been collected for each type of vehicles for the sample size considered. To make a comparison of the observed and VISSIM headways, statistical cumulative frequency plots were drawn.

Other traffic flow parameters like speed were compared between the simulated and observed spot speeds at a mid-block location in a similar approach as described above. Furthermore, VISSIM suggests a recommended desired speed for each vehicle types based on the given inputs and simulation run. The traffic data from field and the output data from the simulations experiments compare favorably with close fit (Figure 4-5), which represent the validity of the models in one aspect. It reveals that the model reasonably represents the observed traffic behavior. Then, percentage errors were calculated based on the average delays, average time headways, average queue length and average travel speed between the observed and simulated results.

Table 1. Calculated errors for traffic performance parameters at Ker-awud intersection

\begin{tabular}{cc}
$\begin{array}{c}\text { Traffic Performance } \\
\text { Parameter }\end{array}$ & $\begin{array}{c}\text { Error (between simulated } \\
\text { and observed values) }\end{array}$ \\
\hline
\end{tabular}




\begin{tabular}{cc}
\hline Delay & $7.54 \%$ \\
Headways & $6.87 \%$ \\
Queue Length & $8.43 \%$ \\
Travel Speed & $9.86 \%$ \\
\hline
\end{tabular}

Table 2. Calculated errors for traffic performance parameters at Tirufat intersection

\begin{tabular}{cc}
\hline $\begin{array}{c}\text { Traffic Performance } \\
\text { Parameter }\end{array}$ & $\begin{array}{c}\text { Error (between simulated } \\
\text { and observed values) }\end{array}$ \\
\hline Headways & $9.64 \%$ \\
Queue Length & $6.46 \%$ \\
Travel Speed & $6.44 \%$ \\
\hline
\end{tabular}

Therefore, all the calculated error percentages for the traffic performance parameters at both Ker-awud and Tirufat intersections (Table 1 and Table 2) were under 10\%, which shows the model was an acceptable representation of the real traffic behavior. For the $1.5 \mathrm{~km}$ study corridor, various simulation results for each vehicle category were extracted in order to make a meaningful validation. To make such validation, the cumulative frequency plot for travel time extracted from VISSIM for vehicle code 360 (Motor Bike) were considered for a selected $1.3 \mathrm{~km}$ length out of the total stretch. From the cumulative frequency distribution plot, the arithmetic mean of the vehicle travel time for vehicle code 650 (Motor Bike) was determined and compared with the actual travel time for Motor Bikes in field, as determined by average speed technique. Then, the percentage error was estimated between the simulated and observed average results.

Table 3. Calculated errors for travel time for vehicle code 650 (Motor Bike) at the $1.3 \mathrm{~km}$ study corridor

\begin{tabular}{cc}
\hline Traffic Performance Parameter & $\begin{array}{c}\text { Error (between simulated and } \\
\text { observed values) }\end{array}$ \\
\hline Travel Time & $5.67 \%$ \\
\hline
\end{tabular}

As a result, the value in Table 3 reveals that the VISSIM simulation model of the $1.5 \mathrm{~km}$ road corridor reasonably represents the observed traffic behavior with an error of $5.67 \%$, which was much less than $10 \%$. Therefore, since all model validation criteria were met with an acceptable margin of error, the models were an accurate representation of the real traffic nature and they could be used for evaluation of various traffic planning strategies.

Unlike the model development and validation approaches in various studies (David et al., 2016; Bhargab et al., 2015; Vedagiri and Jain, 2012; Bhavsar et al., 2007), where one traffic parameter was used for the validation process, this study incorporated multiple parameters to conform the validity of the models. Simulation models cannot be realistic representation of the actual traffic behavior, unless they are verified for their validity from various traffic dimensions, which should be done before conducting any strategy analysis. For instance, David et al. (2016) used only waiting time and Bhargabet al. (2015) used only vehicle delays as a validation criteria, which may not be sufficient to assure the validity of the models. Therefore, this study presented a significant concept regarding the approaches to create an accurate simulation models by considering multiple traffic performance indicators like delays, headways, travel time, queue length and travel speed in order to ensure the validity of the models before conducting various traffic analysis.

\subsection{Application of traffic simulation experiments in Hawassa city}

Hawassa City is experiencing considerable vehicle delays and shocking traffic accident history, because of inefficient traffic management at intersections and main roads. The mitigation attempts to optimize the traffic performance were not satisfactory, due to unscientific and up to date action plans. Therefore, this study contributes to filling the gap regarding the use of modern traffic management approach by considering carefully designed experiments. As presented in this study, any of the cities intersection and road corridors along with various mitigation strategies can be modeled in simulation tools like VISSIM for testing their effectiveness. The behavior of the proposed strategic plan by the City's municipality can be examined with the possible impacts through microscopic simulation along with refined validation, before making any investment.

Therefore, the city administration is expected to employ such kind of modern approaches in order to manage the traffic in an effective and sustainable manner for any design traffic. Efficient and reliable results that meet the societal needs can be achieved if any proposed alternative traffic management strategies are experimented for their impacts in such kind of software tools. Moreover, the city administration and other concerned government agencies should consider periodic traffic data collections and documentation regarding the aspects of traffic service performance. Transport planners and policy makers should consider innovative/ scientific traffic simulation approaches to reduce travel times, improve service management and reliability with tested strategies. This reduces congestion by considering various simulated traffic management solutions, which lift up the beauty of the city. Experience sharing with model cities abroad, employing such kinds of experimented traffic network simulation for their 
setups should be considered. Continuous researches need to be done periodically to assess the service conditions, test new traffic management strategies and evaluate the performance of the operational condition.

\section{Conclusion}

The simulation of the study corridor and the model validation confirmed that any road corridors could accurately be created in VISSIM for detail signal design, traffic management, and various traffic analysis together with efficiency evaluation before implementation of any strategy. The obtained results from the simulation experiments and the comparison with the field traffic behavior assure that the models accurately represent the actual traffic nature with less than a $10 \%$ margin of error. The presented modeling approach has various significance for different real-world practical application, including:

- the development of traffic microsimulation models for any road corridor with all the required data inputs in order to analyze the impacts of traffic engineering strategies;

- the use of coherent approach during the validation of microsimulation models before proceeding to the impact analysis of proposed transport alternative strategy setups;

- the use of multiple traffic performance parameters as validation criteria to confirm the agreement between the simulated models and the real traffic behavior.

It should be stressed that the simulation model development and the validation aspects are prerequisites before considering any strategy analysis in microsimulation tools like PTV VISSIM.

\section{Acknowledgment}

The authors wish to acknowledge all the professionals who contributed to this work; especially, Transport Programs Management Office's (TPMO's) Traffic Safety and management (TSM) division staffs for their technical assistance and provisions of the license to run PTV VISSIM 9.0-07. The authors extend their sincere appreciation for the Ethiopian Roads Authority (ERA) and Hawassa University for funding this research work.

\section{References}

Algers, S., Bernauer, E., Boero, M., Breheret, L., Di Taranto, C., Dougherty, M., Fox, K. and Gabard, J-F., 1997. Review of micro-simulation models, SMARTEST Project Deliverable No. 3, European Commission DGVII, Brussels.

Bhargab, M., Kinjal, B., Roshan, J., Manfred, B., 2015. Micro-simulation based evaluation of queue jump lane at isolated urban intersections: an experience in Kolkata. Journal of Transport Literature, Vol. 9, No. 3, pp. 10-14.

Bhavsar, J.N., Sharma, S., Dhingra, S.L., 2007. Simulating bus priority system for an urban corridor in Mumbai city. 11th World Conference on Transport Research. I.C.T. Pvt. Ltd., A-8 Green Park, New Delhi 110016. Civil Engineering Department, I.I.T., Powai, Mumbai 400076. India.

Currin, T.R., 2001. Spot Speed Study. In Introduction to Traffic Engineering: A Manual for Data Collection and Analysis, ed. B. Stenquist. Stanford, Conn.: Wadsworth Group, pp. 4-12.

David, S., Dusan, J., Peter, T.M., Rafael, M.A., 2016. Traffic Microsimulation Models Assessment - A Case Study of International Land Port of Entry. Paper submitted for presentation at the 7th International Conference on Ambient Systems, Networks and Technologies (ANT 2016). Procedia Computer Science, Vol. 83, pp. 441-448

Duduta, N., Adriazola-Steil, C., Wass, C., Hidalgo, D., Lindau, L.A., John, V.S., 2012. Traffic safety on bus priority systems: Recommendations for integrating safety into the planning, design, and operation of major bus routes. The WRI Ross Center for Sustainable Cities. Washington, District of Columbia. USA.

Fox, K., Hallworth, M., Collier, B., Jones, S., 2000. Strategic Public Transport Priority Using Selective Vehicle Detection - Does it work? Paper presented at the European Transport Conference 2000, Homerton College Cambridge, 11-13 September 2000. PTRC.

Fox, K., Liu, R., 2000. "Do micro-simulation models give the right answers?" Paper Presented at the European Transport Conference 2000, Homerton College Cambridge, 11-13 September 2000. PTRC.

Fox, K., 2011. Introduction to Micro-simulation. Leeds, United Kingdom.

Garber, N.J., Hoel, L.A., 2008. Traffic and Highway Engineering, 4th Ed., University of Virginia: United States of America, Cengage Learning, pp. 99-140.

Jepson, D., Ferreira, L., 1999. Assessing travel time impacts of measures to enhance bus operations. Part I: Past evidence and study methodology. Road and Transport Research Journal, Vol. 8, No. 4, pp. 41-54.

Morellato, C., Sdun, M., 2010. The Use of ITS for Improving Bus Priority at Traffic Signals, Masters Thesis. Trafikdagepå Aalborg Universitet, Department of Transport, Technical University of Denmark. 
Oshyani, M.F., Cats, O., 2016. Evaluating the performance and benefits of bus priority, operation and control measures. Paper Submitted for Presentation at the 95th Annual Meeting of the Transportation Research Board, Washington

Papadopoulou, S., Papamichail, I., Roncoli, C., Bekiaris-Liberis, N., Papageorgiou, M., 2018. Microscopic simulation-based validation of a per-lane traffic state estimation scheme for highways with connected vehicles. Transportation Research Part C, Vol. 86, pp. 441-452.

Papageorgiou, G., Damianou, P., Pitsilides, A., Thrasos, A., Ioannou, P., 2006. A microscopic traffic simulation model for transportation planning in Cyprus. International Conference on Intelligent Systems and Computing: Theory and Applications, pp. 157-166.

Shawn, M.T., William, L.E., Robert, J.B., Douglas, J.H., 1998. Travel Time Data Collection Handbook: Texas Transport Institute. The Texas A\&M University System: Collage station, Texas 77843-3135, USA.

Vedagiri, P., Jain, J., 2012. Simulating performance impacts of bus priority measures. ACEE International Journal on Transportation and Urban Development, Vol. 2, No. 1, pp. 15-19.

\section{Biographical notes}

Robel Desta received a BSc degree in Civil Engineering and an MSc degree in Road and Transport Engineering from Hawassa University. He is currently working as a Senior Lecturer and Researcher with Hawassa University, Institute of Technology (IoT), School of Civil Engineering,Hawassa, Ethiopia.

Bikila Teklu received a PhD degree in Transportation Engineering from the University of Mississippi, USA and currently working as Assistant professor of Civil Engineering with Addis Ababa University, Institute of Technology (AAiT), School of Civil and Environmental Engineering, Addis Ababa, Ethiopia.

Mihret Dananto received a PhD degree in Municipal Engineering from Wuhan University of Technology, China and currently working as Assistant professor of Civil Engineering with Hawassa University, Institute of Technology (IoT), School of Bio-system and Environmental Engineering, Hawassa, Ethiopia.

Received June 2018

Accepted August 2018

Final acceptance in revised form September 2018 